\title{
Measuring Human Risks in Service: A New Model
}

\author{
Silvio Barbieri' ${ }^{1}$ Emmanuel Fragniere ${ }^{1}$, Yvonne de Grandbois ${ }^{2}$, Pedro Miguel Moreira ${ }^{1}$ \\ ${ }^{1}$ University of Applied Sciences Western Switzerland, HES-SO, Delémont, Switzerland \\ ${ }^{2}$ Montreux Business University, Montreux, Switzerland \\ Email: barbieri.sil@gmail.com, emmanuel.fragniere@hevs.ch,yvonne.grandbois@gmail.com, \\ pedro_miguel.moreira@hotmail.com
}

How to cite this paper: Barbieri, S., Fragniere, E., de Grandbois, Y. and Moreira, P.M. (2017) Measuring Human Risks in Service: A New Model. Journal of Service Science and Management, 10, 518-536. https://doi.org/10.4236/jssm.2017.106040

Received: November 14, 2017

Accepted: December 16, 2017

Published: December 19, 2017

Copyright () 2017 by authors and Scientific Research Publishing Inc. This work is licensed under the Creative Commons Attribution International License (CC BY 4.0).

http://creativecommons.org/licenses/by/4.0/

\begin{abstract}
The modeling of a customer experience realized through a service blueprint is useful for visualizing the structures and processes involved in its production. However, the classical service blueprint fails to consider the contribution of human factors-motivation, emotion, satisfaction, etc.-that are essential elements of service interactions and can represent important risks of non-quality. Consequently, we have developed an enhanced service blueprint dedicated to Enterprise Risk Management (ERM), which includes the human factor dimension. In order to take into account the human factor dimension in the service blueprinting syntax, we include a sociogram. A sociogram is a graph whose nodes are linked together by arrows expressing sociological and psychological variables. Thus we are able to measure and visually identify the areas at risk in an integrated manner, those which are typically attached to the dominant human factor component of service productions. To illustrate this new ERM modeling concept, we have developed a case study related to a service at the reception of a luxury hotel. We are thus able to show the advantages of using the service blueprinting approach compared to the classical risk mapping process in the context of ERM.
\end{abstract}

\section{Keywords}

Enterprise Risk Management, Service Blueprint, Sociogram, and Human Risk

\section{Introduction}

The purpose of this paper is to show the importance of human factors when dealing with risks in service experiences. To this end, we have developed a new model called the "riskoprint" based on multiple experiments conducted at the University of Applied Sciences Western Switzerland (HES-SO) with MSc stu- 
dents in Service Management and Engineering and with MBA students in Enterprise Risk Management. The model has been tested in our consulting activities in sectors such as travel agencies, libraries, welcome desks, the police, various departments in public services (traditional and online), private banks, and others [1].

A service acquires value once the client perceives the benefits of it. Today, most of these salient attributes (i.e. elements of perceived value) are perceived during the service experience itself, when the process of service co-creation occurs between clients and the service provider. As a result, when developing an enterprise risk management approach, the full scope of cultural, operational, and experiential contexts from the perspectives of both the service provider and the client is needed [2] [3]. Enterprise Risk Management in this context should take into account that it is mainly the client value perception that needs to be protected. Risks are consequently of human origin.

To address these human risks in service productions, we propose a new model combining service blueprinting (for the visualization of the service experience) with sociograms (to measure elements of human interactions).

For illustration in this paper, we have applied our new modeling approach to address a human-related problem through a service experience at the reception of a luxury hotel. In this regard, we have designed a methodology to highlight the service experience with the key actors, and to identify and locate risk areas, with the ultimate goal of understanding, solving, decreasing, or anticipating human problems or risks.

In general terms, the concept of our proposal is to further integrate human value directly into the service blueprinting method. To achieve this, we used the blueprint mix, which traces and presents the service experience for each actor from the beginning to the end of the journey, along with the sociogram, which highlights how the actors interact with each other and the quality of the connections. This allows us to focus on the human component. In a risk management context, our approach (named the "riskoprint") could be compared to the COSO model or conventional risk mapping, with the classic colors borrowed from heat maps: red, yellow or orange and green. One could therefore measure the human risk in its whole or integrated way throughout the service experience through the interaction zone for all the actors involved.

The riskoprint could be an original human risk management tool for services (re)design and risk management. In addition, the riskoprint should be used to map risk areas at the human level throughout the service life through service blueprinting. This concept could be paralleled with the explorer who would draw his geographical map throughout his journey. The representation of the itinerary could thus correspond to the actor's life journey during the service experience. The key actors would be the populations encountered by the explorer, and the obstacles could be the different dysfunctions that can happen all along the way. The map would serve as a tool for the journey, highlighting the areas lived or discovered, and locating treasures or salient attributes (i.e. elements of 
perceived value). In the case of service and service blueprinting, the map does not represent different geographical areas, but rather different mental zones. In addition, the mix between the service blueprint and the risk map enables us to concretely visualize the zones of the service which may pose a problem or risk.

This paper is organized as follows: In Section 2, we present a literature review showing the important scientific work related to human risk in the service experience. We see that in most cases these risks are partially addressed; In Section 3, we define the notion of human risk and explain how it is integrated in enterprise risk management (ERM) standards. We also explain the practical service blueprinting approach as well as the sociogram and their relationship to human risk; In Section 4, we develop a full case study in hospitality management. We start with a detailed storyline depicting the entire service experience. Then we model it with the blueprint. Finally, we zoom in on the decisive service interaction thanks to the sociogram enabling us to address the human risk; In Section 5, we conclude by once more explaining the logic of mixing service blueprinting and the sociogram. We also propose an integrated modeling tool that adds a risk map to the blueprint and the sociogram in order to monitor the human risk along the overall service experience.

\section{Literature Review}

The scientific literature about human risk arising in the service experience is huge. As our main objective is to improve risk management for services, we have thus concentrated our review on three domains related to service blueprinting, sociograms, and enterprise risk management (ERM). The goal of this thorough literature review is to establish links among these three important domains to develop a new approach to risk management for services.

The modeling of a service production, usually referred to as a service blueprint, is often conceptualized in a linear or matrix form [4] [5]. These models, while useful for visualizing the structures and processes involved in service production, fail to consider the contribution of human factors-motivation, emotion, satisfaction, etc. - that are also essential elements of service interactions. It is therefore necessary to focus on the satisfaction and behavior of customers and employees.

A sociogram is defined as a "sociometric diagram representing the pattern of relationships between individuals in a group, usually expressed in terms of which persons they prefer to associate with" (Random House Dictionary). Using this instrument we are able to measure risks which reflect the dominant human factor component of service productions. The sociogram can be used to model a human problem contained within group interactions in order to provide a solution. For example, using the sociogram we can see if there is some pressure concentrated on a single person within the group, and once it is discovered we can protect this person. It can thus show the interactions in the service experience, measure the mood (satisfaction, etc.) of the people in the inter-connections, and identify human risks. The aim is to focus on the human factor and thus protect 
the service in question.

Enterprise Risk Management (ERM) encompasses all the means a company can employ to increase its chances of reaching its business objectives. The two main ERM standards are COSO ERM and ISO 31000. COSO (Committee of Sponsoring Organizations of the Treadway Commission) is an internal control framework and ISO 31000 is a family of risk management standards codified by the International Organization for Standardization. These standards provide principles, frameworks and guidelines for managing any form of risk. To our knowledge the notion of psychological risk (or human risk) is not explicitly mentioned in these standards [6] [7]. This lapse is unfortunate, as today more and more service companies are affected by these risks and are not properly equipped to address them (e.g. employee burn-out and demotivation, and clients' lack of loyalty).

We include this literature review to show that service blueprinting, sociograms and ERM approaches are solely addressing a part of the human risk management problematic in service production. There is a need to develop a transdisciplinary research approach in these areas.

[8] demonstrated that the experiments of service are based on interactions between several parties. Some interactions are visible while others are not. The perception of the customer, compared with the service experience, makes him a co-producer. [9] showed that any dysfunction between the actors of the service can have fatal effects on the supplied service offer. Medium and large companies suffer from it, because of their size and related structure. To solve this problem, these authors proposed a directed graph model, weighted and generalized (Weighted Generalized Directed Graph: WGDG) that combines the service blueprint with the determination of an optimal management of interactions between involved parties. [10] emphasized that to handle the problems of interactions within a group, it is necessary to identify the people susceptible to changing behavior during the service experience. In their model, every interaction between two members of the same group is visually represented by a connection. The resulting plan is used to analyze the internal social networks, which in their turn help to identify the key attributes leading to the proper functioning of the whole group. Their research also aimed at detecting the number of intermediaries who existed between two specific entities of contact (i.e. touchpoint). [11] showed that by using a sociogram, it was possible to visualize the dyadic interactions between two parties in a context of experience. He was able to demonstrate that with this visual tool, it was possible to connect events originally separated. Using this technique, [12] conducted a study on aggression in schools. Their research led to the development of a graphic model, which combines the sociogram and statistics to determine if certain populations seem more affected than others by the problems of aggression. This type of analysis allowed [13] to realize a service model that adapts itself automatically when a failure is detected through an analysis of human behavior. This type of service modeling uses tech- 
niques of data processing to rethink the behavior observed within the service offer.

[5] observed that the service blueprinting approach and in a general way the graphic modeling of a service, places the customer at the heart of the activity. It allows the company to concentrate itself on the key points of the service, in order to improve it and create value. The visual modeling of the human interactions can be useful not only for the companies of service, but also to handle much more complex questions for the company. [14] made an empirical study on the use of the analysis of the social networks (SNA: Social Network Analysis), which aims to identify the necessary relations within a country's government during a war (e.g. Afghanistan) to reassure, stabilize, or reconstruct a country.

[15] have developed a graphic tool that connects customer expectations with the company's expectations. Thus, a sociogram allows better understanding of group dynamics. [16] led an experiment in a Spanish university in Castilla-La Mancha to determine how a group works, to understand the elements in connection with the organization, the relations between the interactions, and finally the group dynamics. They discovered that certain group dynamics such as the intensity of the relations between its members, and the level of cohesion plus the level of socialization of every member in the group represented crucial points. [17] were interested in the collaboration between partners and showed that these could succeed only if the project's participants shared a common objective. On the basis of an analysis of social networks within an educational institution, [18] identified the specific characteristics of the key people of an organization to optimize and facilitate corresponding human interactions. [19] conducted a research project on the impact of interactional difficulties between different parts of a given service experience. They established that the employees, who were in direct contact with the public (i.e. customers), could be under great psychological pressure from customers. This continuous exposure negatively affected the behavior of the employee in the medium and long-term. [20] observed the phenomenon of retention of knowledge and information in a Scottish prison. They noticed that this loss of conscious awareness could undermine the stability of a penitentiary. By using an analysis of social networking, they demonstrated that the hierarchical structure does not guarantee a good performance. [21] examined the existing theories on the social networks and their analysis. He schematized a series of interactions and hierarchical levels between the various groups. He found that in some cases solely the sociological phenomenon of cliques was visible. [22] conducted a study on the relationship between the students of the Open University, namely a distance learning university. They employed the SNA (Social Network Analysis) to establish the links that students maintain between themselves in the city of Kupang (and in connection with the university).

To understand the functioning of social networks, [23] wanted to test the concept of system reliability in an empirical manner. To do this, he examined 
whether the information obtained through the formal structures organized by a company was the same compared to the information obtained through informal structures. They discovered that the informal structures could have a negative impact on the performance and the risks of the company. The SNA approach is also used in the medical domain. For example, to better understand how a medical institution worked, [24] studied the integration of health professionals in multidisciplinary teams. He discovered that when a new healthcare professional had been trained beforehand, the rate of new staff integration success was much higher. As the social networks are generally constituted by human beings, [25] was interested in the importance of emotional intelligence in the workplace. $\mathrm{He}$ explored the existing theories and described the Bar-on, the Mayer and Salovey, and the Goleman. The methodology of the Bar-on defines the emotional quotient as the opposite of the intelligence quotient (cognitive intelligence). Emotional intelligence was represented by a graphical modeling by [26]. It is divided into four themes: perceiving the feelings; using the feelings; understanding the feelings; and managing the feelings. This last theme is an adaptation of a theory developed by [27].

Regarding the practical modeling of these concepts, [28] conducted an empirical study on the challenges of implementing a quality management system. They identified five main challenges: the lack of management support for the implementation of such a system; the human resources management (quality management); the lack of corporate control on customer needs; the lack of planning of the qualitative aspects; and the lack of appropriate systems and resources that allow setting up a system like this.

[29] highlighted the importance of hybrid services. This means that a service is established at the same time by technological, human, and informative interactions. Moreover, an increase in services requires that the customer interacts directly with the technology. The perception of the customer, with regard to this type of service, is based on three variables, namely the quality of the interaction, the quality of the technology, and the quality of auxiliary aids provided to the customers.

E-mail is an extremely useful tool to analyze the interaction between people. [30] analyzed the electronic communications exchanged between the employees of the company, as well as the interactions between colleagues, to understand how the company worked. According to their study, traditional methods, such as processes and procedures, have been considered not performing well enough to manage information. In fact, it is necessary to have the good person at the right place in order to better share information. They developed the model of the Matchmaker Index to determine which employees were the best adapted to work together in the various departments of the company.

To interact, certain qualities are required. [31] began a study on the creativity within the working groups. They established that the members who had a particular set of character traits were better able to produce quality work and thus create a dynamic group. They identified the following attributes as being crucial: 
having an open mind (for innovation); being able to trust each other; and being socially competent (able to interact and communicate with others, etc.). However, some basic conditions must be organized to promote the collaboration between the employees. This task was not easy, as showed by [32], who conducted an empirical study on enterprise management changes and their impact on the internal and external relations. [33] revisited the evolution of the existing theories on "the actor-network", which indicates that a network is implemented on the basis of several negotiations with regard to the task every actor is supposed to carry out. A service can be permanently improved. [34] showed that the " $5 \mathrm{~S}$ " technique (which is translated into English as: sort, set in order, shine, standardize, and sustain) allows a company or a service to improve its performance. This methodology is based on some fundamental principles of the organization, like communication, discipline, normalization, and implication of the resources which help a company to constantly improve. [35] observed in a study that the aspects of a service, such as the price, the performance level or the IT support, were also completely neglected.

The concept of "Value Proposition Design" consists of a method that uses the "Business Model Canvas" [36]. It serves as a guide for creating products and services that the customers really want. The central idea is to avoid the risk of wasting time, energy, and money, for products and services that will ultimately not sell. This methodology can be used by the decision-maker to better organize the information, manage the value proposition more effectively, have a common vocabulary, bring reactivity, avoid wasting time, reduce the risk of failure, focus on the essentials, concretely test the ideas, and finally bring the requested item to or solve the problem of the end customer [37].

Following this literature review on the topics of enterprise risk management, service blueprinting and sociograms, we see that the notion of human risk within the service experience is definitely addressed, although only partially. To our knowledge, the model we propose is the first one that mixes elements of risk management, service blueprint and the sociogram in order to address in a coherent manner the human risks present in the service experience.

\section{Human Risk Addressed through the Sociogram and Blueprinting}

According to the Oxford Online Dictionary (2017), risk means: " $A$ situation involving exposure to danger, the possibility that something unpleasant or unwelcome will happen; a possibility of harm or damage against which something is insured; or the possibility of financial loss". Risks are correlated with a decision taken. For example when you make a decision to invest in a bond or share market you will be automatically exposed to a potential loss. This exposure is called a risk. When you lose money this risk becomes effective. For [38], there are different typologies of risk that they have identified as: financial, performance, physical, psychological, and social risk. Psychological and social risks tend to be 
treated together isolated from the other risks. They are however definitely part of ERM. Indeed, if you are psychologically unstable, the way you interact socially or with your colleagues can expose both you and your company to a risk.

Everybody is exposed to risks but especially enterprises. After many scandals due to a lack of risk management, enterprises became more sensitive to that problematic and some standards have been introduced to manage risk more efficiently. Enterprise Risk Management (ERM) has been developed to reduce risk exposure inside enterprises, and as mentioned earlier, ERM like COSO and ISO 31000 have been created and are today deployed in most companies in the world.

It is very difficult to have a global model because every company is exposed to specific risks. [39] and [40] have shown that the presence of a Big Four auditor, the independence of the board and the support of the CFO and CEO are crucial to the implementation of an Enterprise Risk Management System (ERM). Enterprise Risk Management creates value for shareholders because it allows companies to have a look at risks from a macro and micro point of view. From the macro side because enterprises have to identify external risks active in their environment (market, economy). From the micro side because ERM allows companies to identify potential risks inside a business unit [41]. A study on the management of risk in companies and the notion of performance, [42] shows a relationship between the implementation of an Enterprise Risk Management system and enterprise performance. Some argue that the impact of ERM is quite limited because performance depends on many other factors such as environment uncertainty, industry competition and company complexity [42].

Nonetheless, there are studies that show that an implementation of ERM and the value of a company are positively correlated [43]. Actual models are limited, however, and don't take into account the social interaction between several members of a group, which can be a source of risk inside a business unit.

To measure the human interaction within a service experience we are using a second visualizing model that is called the sociogram, a tool developed in the 1930's by Jakob Levy Moreno to show social interaction. The sociogram focuses on the interactions between all the actors, and on the quality of its interactions from a human point of view. It mixes graph theory from operations research as well as from sociology. In operations research it is used to optimize networks. The sociogram adds some metrics to graph theory to evaluate the human interactions within social networks, like emotions.

In terms of risk, the sociogram can show the individual well-being resulting from service experience interactions. The main idea is to understand and limit the risks of an incident due to a human factor in service.

The sociogram can also define who is rejected or popular inside a group and helps to create group dynamics and maintain motivation [44]. Social network analysis provides both a visual and a mathematical analysis of human relationships [45]. It is possible however to define influences and power distribution inside a group [46]. The sociogram allows analyzing information and for these 
reasons it is used in many sectors [47]. To sum up, the sociogram could be very useful in services to identify poor and weak interactions during the service experience.

In parallel, there is a tool called service blueprinting which allows creating a picture of an entire service experience, but it is limited because it doesn't take social and human interactions into account. As we know, interaction is crucial to maintaining a high quality service. The blueprint allows the mapping and modeling of an ecosystem in a service experience [48].

The service blueprinting approach can serve as a visual tool schematizing the complete service experience, whereas the sociogram allows the interactions between the various actors present in the whole service experience to be more visible. Therefore, the combination of both tools is going to allow the modeling of individual and social well-being. By using this combination, it is thus possible to know the state of mind of an actor during the service experience, and how he interacts with his interlocutors.

In a general way, service blueprinting corresponds to a simplified representation of a service experience [49]. The blueprint is often realized in the form of a matrix with two axes (see Figure 1). The horizontal axis includes the various stages of life of the service, while the various actors are identified on the vertical axis. The horizontal axis is divided into three parts, namely: 1 ) the pre-transaction, which is the phase that precedes the contact with the customer; 2) the transaction, which corresponds to the basic service (with the additional services); and finally 3 ) the post-transaction which we could call the "after-sales service", although this term too often has a negative connotation. The vertical axis stages all the actors involved in the service experience, such as the customer, the front office, the back office, as well as the support. The customer is the beneficiary of the service, whereas the front office represents the provider of the service who is directly in contact with the customer. The back office concerns the employees who are behind the service offer, and who administer or support the front office. In the center of the matrix are the actions and events associated with every actor, according to the various stages of life of the service in question. Finally, the progress of the service experience is divided by a "line of visibility" which distinguishes the visible and non-visible parts of the service, namely the front and the back office.

\section{A Case Study on Hospitality Management}

\subsection{The Practical Case with the Use of the Blueprint}

To illustrate our concept, we imagined a service experience in the luxury hotel business by combining the service blueprinting tool and the sociogram tool. To make this service experience visible we modeled an existing timeline (see below), which we transcribed on a first blueprint (see Figure 2). This blueprint presents the basic service experience (macro vision). Using the sociogram, a zooming in is done on a specific interaction described in the blueprint and the 


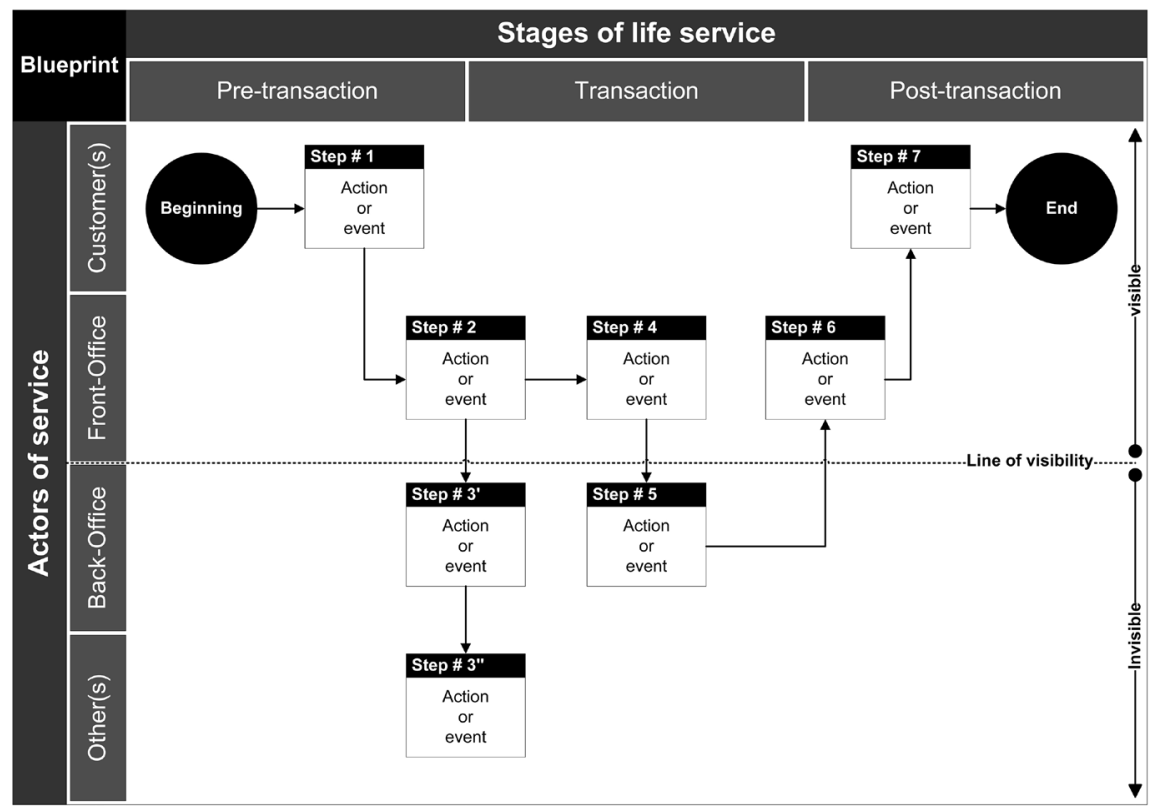

Figure 1. The blueprint model (source: authors of this paper, adapted from Lovelock, Wirtz, Lapert and Munos, 2014).

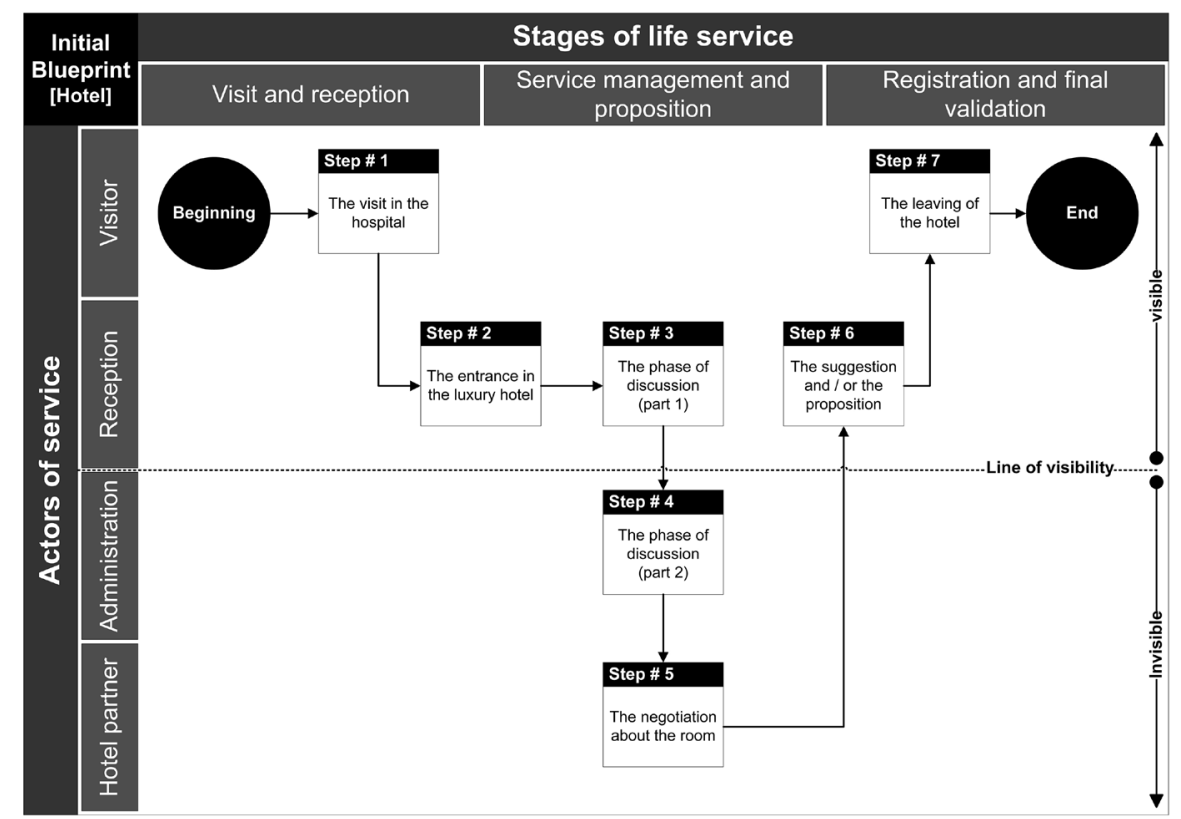

Figure 2. The initial blueprint of the practical case of the hotel with a first analysis, macro view of the basic service experience (source: authors of this paper).

service experience in question (see Figure 3 for the zoom-in and Figure 4 for the macro-sociogram). Figure 4 concentrates thus on the human interactions involved in this area of the service life path. The final objective is to think about a proposal for the solution, optimization, improvement or protection of the service. The improved blueprint (see Figure 5) shows the proposed solution, or in this case, the way the hotel can anticipate these kinds of questions (e.g. advance agreement). 


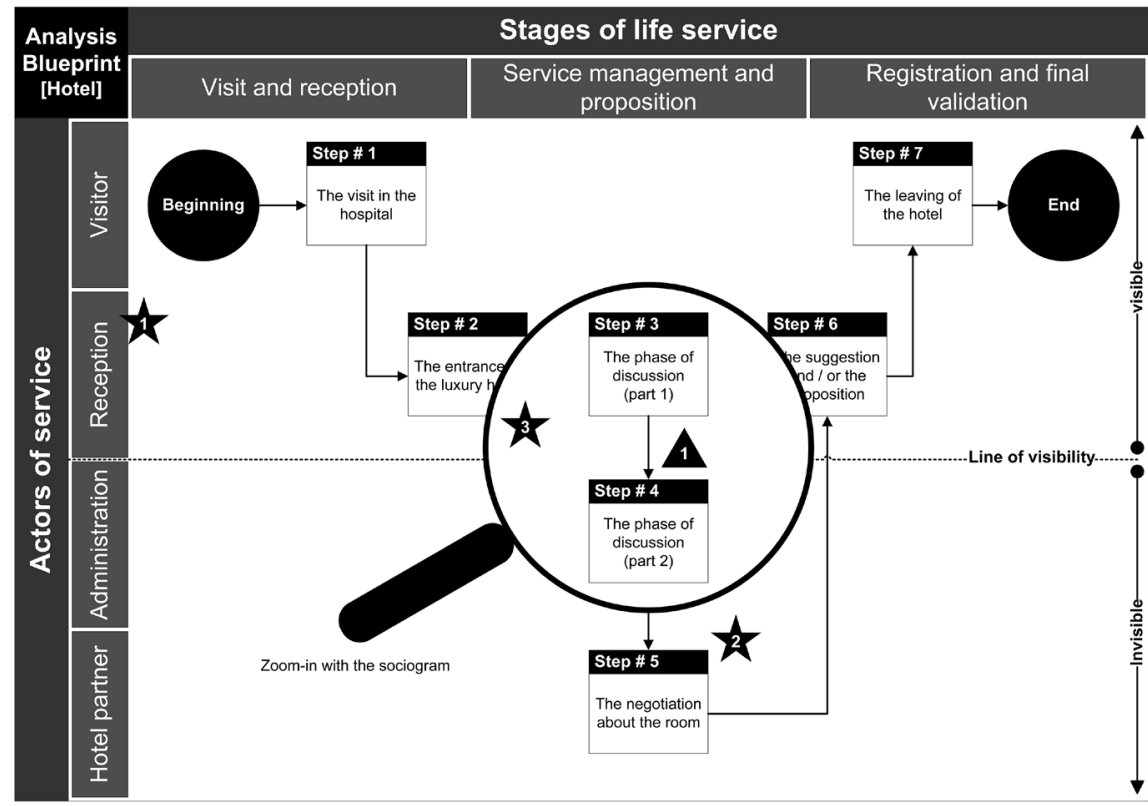

Figure 3. The initial blueprint of the practical case of the hotel with a zoom-in of the main human interactions within the service experience (source: authors of this paper). Legend of Figure 3: $\$$ : (Medium salient attribute) Reception; attribute) Price; (Low salient attribute) Speed; $\mathbf{\Lambda}$ : (Dysfunction, risk or defect) No adequate solution.

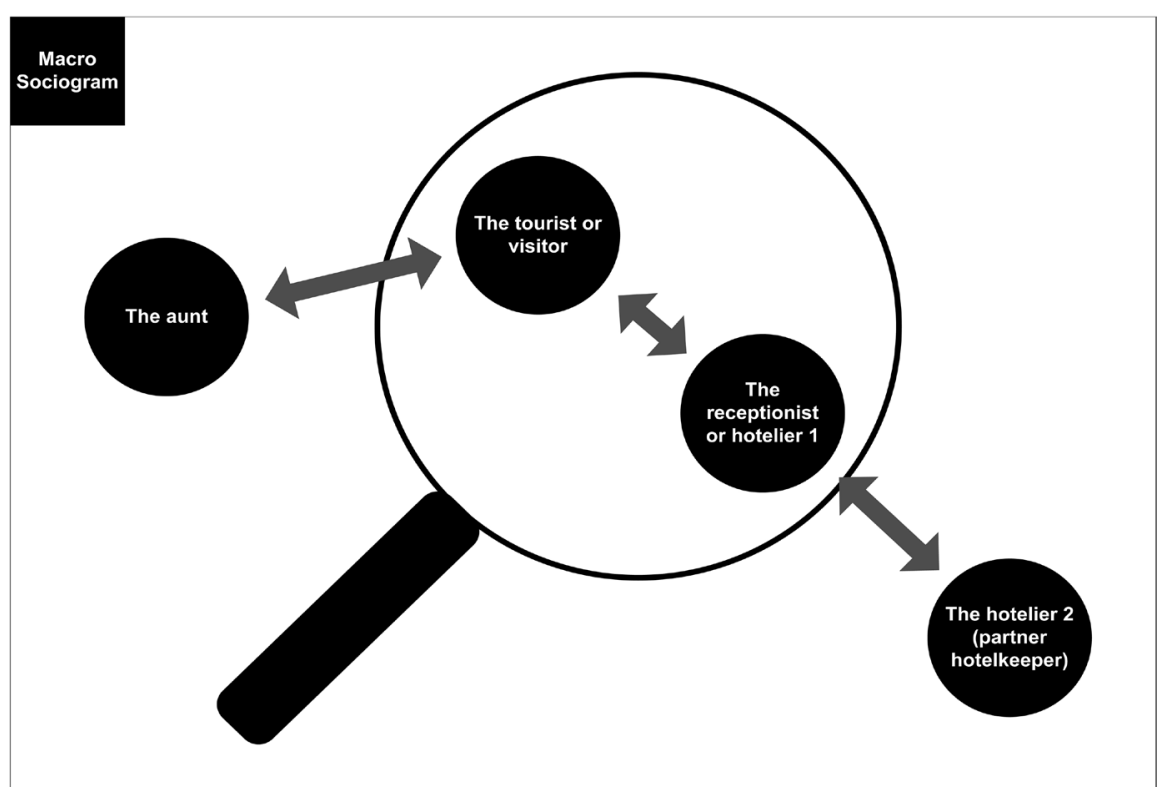

Figure 4. The macro sociogram of the practical case for the hotel: a zoom-in of the main human interactions within the service experience (source: authors of this paper).

In this case, the service blueprinting tool is used in order to have a macro view. The main steps are: 1) the realization of a first basic blueprint; 2) the identification of the salient attributes of the service, those characteristics which define the notion of value to the client; 3 ) the social, protective, economic and environmental analysis; 4 ) the problem (or risk in our case) analysis with warnings, 


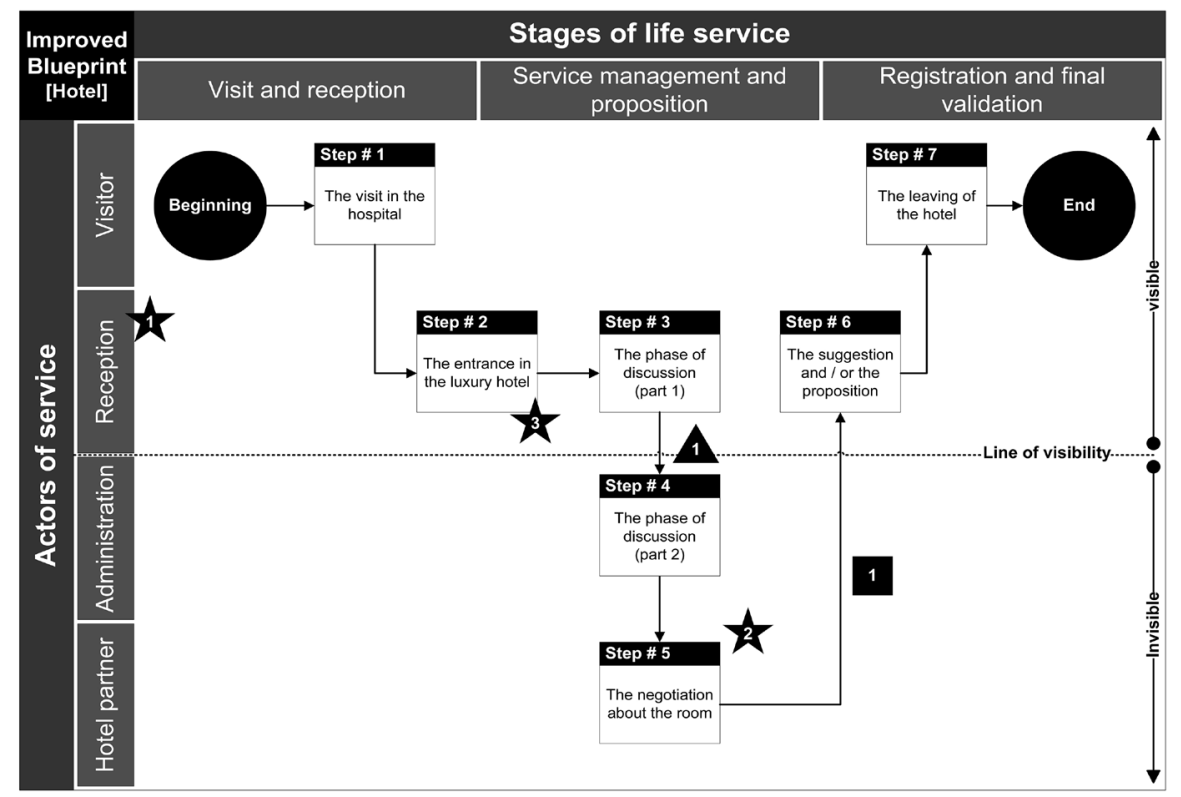

Figure 5. The improved blueprint of the practical case for the hotel with a solution, macro view of the basic service experience, (source: authors of this paper). Legend of Figure 5: $\lambda$ : (Medium salient attribute) Reception; $\lambda$ : (Important salient attribute) Price; : (Low salient attribute) Speed; 1 : (Point of anticipation) Advance agreement.

and the work on proposals for improvement and solutions (expectations, risk management, service protection, optimizing delivery, etc.); 5) the creation of a second improved blueprint; 6) the achievement of an action plan for the proposed solutions; and 7) the preparation of a final report. Finally, the micro-zoom analyzed with the sociogram allows a focus on the main human risk contained within the service experience, and helps to highlight the concerned human interactions.

The narrative timeline:

1) A businessman has to go from Berlin to Geneva to visit a client and also see his beloved aunt who is in the hospital;

2) This person goes first of all to the hospital in the city centre to see his aunt;

3) He then leaves the hospital, and he meets his client in a cafe downtown;

4) After the coffee, he returns to the city centre to find a hotel for the night (with the condition that he pays a maximum of 120 Swiss francs for one night);

5) The man tries several hotels, but without success. Tired, he finally goes into a luxury hotel and asks to see the receptionist. This phase is important, because in service, the first contact is decisive;

6) The receptionist is not really friendly at first. He mentions that he has no room for one night at that price. There is a problem at this level, because the price is important to this customer;

7) The businessman begins to feel very tired and stressed, and he continues to insist with the receptionist;

8) The receptionist asks him to wait a moment and he makes a phone call to a partner hotel. This point is crucial. This is where, using the sociogram, we can 
explore different kinds of solutions, relying on the overall quality of interactions;

9) After a few minutes, the receptionist suggests a cheaper hotel not far away. The receptionist realizes that he has to hurry, because the client is really tired;

10) The receptionist proposes to call the hotel himself to make the reservation. The hotel in question confirms the reservation and the receptionist gives him the directions to the other hotel;

11) The businessman thanks him and leaves the hotel.

The representation of the initial blueprint (see Figure 2) makes the life course of the service visible by the client and by the other actors. If we follow the timeline, we can see that the customer is tired and that he quickly seeks a hotel with a fixed price. Moreover, in most services, the first contact is often decisive. The three main salient attributes are the reception, the price and the speed of the service in question. At this level, the point of dysfunction is the service management carried out by the reception of the hotel. In this context, how can we improve or anticipate this kind of problem? In our example, the receptionist contacts a partner hotel, and solves the client's main problem. But, can we do better? Can we show a better image of the hotel? And how can we work on these purely human aspects? The next iteration is to re-draw a new (and improved) blueprint with a concrete solution (proposal) and a new way of service for future customers. Finally, the use of the sociogram coupled with the blueprint tool will help us to analyze the human interactions involved. Now, you have to imagine the following.

This second iteration gives an overview of the proposed improvement of this service experience. Indeed, the idea is to develop a real agreement or partnership contract between different hotels, in order to widen the scope of action and thus to be able to better respond to the expectations of the customers. The macro sociogram shows the various social ties present between the actors. The businessman (or the principal client) comes to visit his aunt in the hospital, then he makes his first contact with the receptionist, who himself is in contact with a partner hotel (another receptionist). The resolution is made and an improvement point is defined. From this point of view, how could we evaluate and quantify this service experience? The blueprint allows us to represent the service from the beginning to the end of the experiment. It highlights the main actors as well as the various events and actions. In addition, the sociogram gives the possibility to zoom in on one or more phases of the service in question, and to understand how the actors interact. But, to quantify this human service problem, one solution would be to evaluate the level of happiness of the actors (i.e. any persons involved in the service experience). For this, we imagined that a negative value would correspond to a dissatisfied customer (or actor), and a positive value would correspond to a satisfied actor. The sociogram could thus contain numerical values (from -1 : unsatisfied actor, 0 : actor on expectation and +1 : satisfied actor).

\subsection{The Practical Case with the Use of the Sociogram}

As mentioned above, our approach aims to link the tool of the blueprint with the 
sociogram view. After having represented and analyzed the service experience with the blueprint, the use of the sociogram approach allows us to focus on a phase of the service. The goal is to understand (or highlight) how actors interact with one another. The interest is to bring out the various social ties as well as the quality of the interactions in question. By following the practical case of the hotel (see previous workflow and blueprints), we could use the sociogram tool coupled with the blueprint method. We could even model an encrypted sociogram representing an initial situation (with a basic level of satisfaction), and an improved final situation (with a more optimal level of satisfaction). To do this, we propose two sociograms where one represents the initial values or the basic mood state of the actors concerned, and a second sociogram that shows the final (expected) values and new mood state at the end of the service experience.

To present the part with the sociogram, we again start from the storyline. At the beginning and at the end of the story, we assume different data sets (these values have been chosen arbitrarily solely to illustrate our approach; in a real case the data are typically gathered through survey research). The data sets are presented below and integrated in figures 6 and 7.

- Starting phase: tourist (1), aunt (-3), hotelier 1 (3), colleague (1) and hotelier 2 (11);

- Final phase (without improvement, see Figure 6): tourist (6), aunt (-2), hotelier 1 (11), colleague (1) and hotelier 2 (11);

- Final phase (with the improvement, see Figure 7): tourist $(8=6+2)$, aunt $(-2)$, hotelier $1(14=11+3)$, colleague $(1)$ and hotelier $2(14=11+3)$.

This last iteration with the improvement (see Figure 7) demonstrates visually and quantitatively that the fact of having established a contract or partnership between the main hotel and the partner hotel, increases the level of satisfaction and the mood of the customer. The (result of) total value for the basic sociogram experience is: $((-2)+(6)+(11)+(1)+(11))=27$, and the (total) value of the new service life path is: $((-2)+(8)+(14)+(1)+(14))=35$. In addition, the level of the satisfaction of the customer rose from 1 to 2 (with an increase of +1 ), while the receptionist also increased his level of well-being from 4 to 5 (with an increase of +1 ). Having a partnership agreement allows the receptionist to better respond to the clients. It can also allow him to be empowered in his daily work, and thus increase his well-being. As a result, the receptionist will surely be more comfortable with the client, maybe less stressed and tired, and this situation will be felt by the final customer.

\section{Conclusions}

The human personal experience is not well integrated within the existing tools of service blueprinting. The actor's profile, feelings and motivations are not taken sufficiently into account as well. Consequently, we have developed an improved visual tool where management would become a greater part of the process of value creation. 


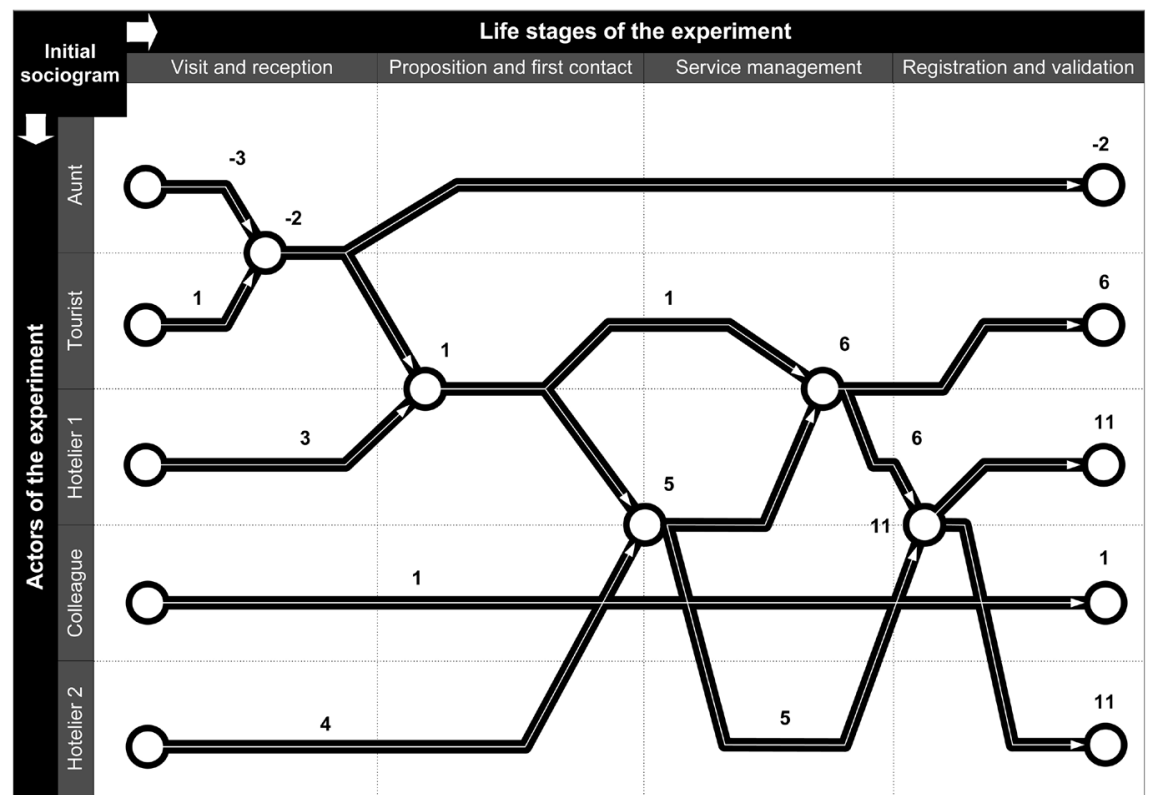

Figure 6. The final sociogram, solution without the improvement, (source: authors of this paper).

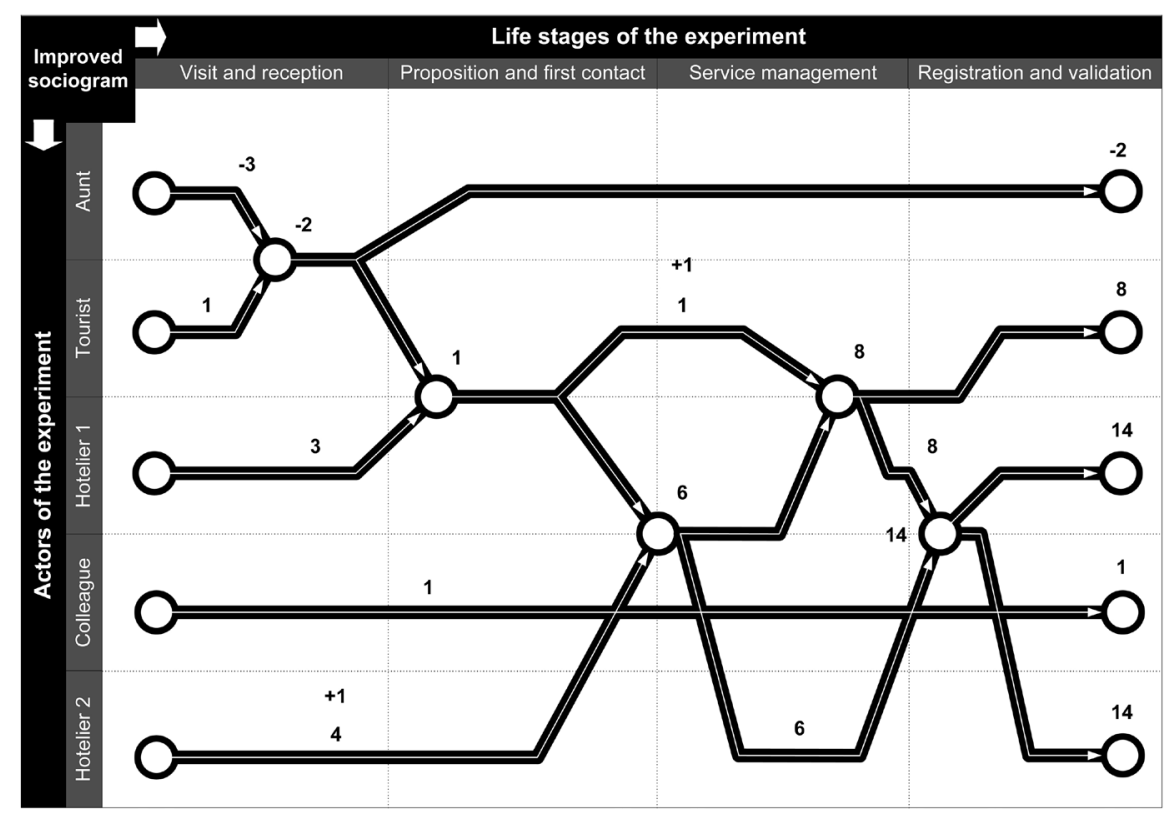

Figure 7. The final sociogram, solution with the improvement, (source: authors of this paper).

Our primary objective going forward is to work at several levels to sharpen the use of service blueprinting while remaining focused on the human risk aspects that are essential to understanding service delivery. The mix of the blueprint and sociogram tools allows simultaneous observation of the health status of different actors, of the service itself, and of the business. To achieve all of our reflection, we conceptualized a new kind of blueprint, namely the "riskoprint" (see proposition in Figure 8). 


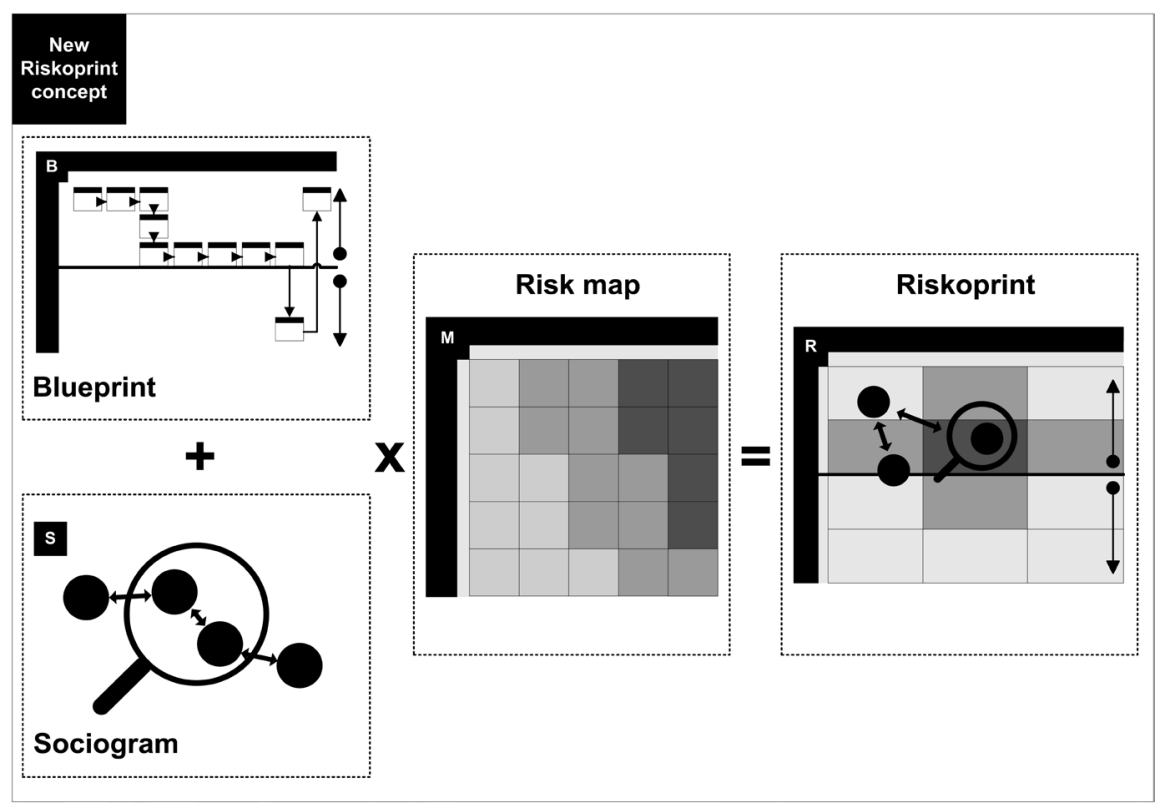

Figure 8. The riskoprint concept: overview of the concept proposed in this paper with the mixing of the blueprint tool and the sociogram (source: authors of this paper).

We have developed a visual model which includes three dimensions i.e. blueprint, sociogram and risk map. This three-dimensional matrix is used to display the degree of intensity experienced by actors during a service experience.

We start with the blueprint. The horizontal dimension (the service life stages) concerns the chronology of the service from start to end. The phase of pre-transaction (A) defines what happens before the service, while the post-transaction phase (C) presents what happens after the service. The transaction (B) concerns the progress of the service. The vertical dimension (the actors of the service) shows the type of person involved in the service experience as a whole. This corresponds to the logic of the classical blueprint.

Secondly, we present the sociogram. The main risk in the service experience corresponds to the human risk. The human is in the centre of the service, and the service experience consists of a multitude of human interactions. The blueprint presents and orders the service experience and the sociogram focuses on the human exchanges present throughout the service (or value) chain. Indeed, thanks to the sociogram, the zoom-in allows us to assess the level to which the service is experienced and perceived by the actors involved, and in particular the customer's perspective.

Finally, we add a third layer in the riskoprint that corresponds to a risk map. The risk map collects the risk information according to impact and probability from the sociogram and enables us to monitor the risks present in the blueprint and address them thanks to proper mitigation. We are currently coding the riskoprint based on $\mathrm{R}$ packages.

\section{References}

[1] Barbieri, S., Fragnière, E., Sitten, M.S. and Zambrano, G. (2013) Proposal of Me- 
thodology to Integrate the Human Factor in the Service Blueprint. Journal of Advanced Management Science, 1, 207-213.

[2] Fragnière, E., Nanchen, B. and Sitten, M. (2012) Performing Service Design Experiments Using Ethnomethodology and Theatre-Based Reenactment: A Swiss Ski Resort Case Study. Service Science, 4, 89-100. https://doi.org/10.1287/serv.1120.0008

[3] De Grandbois, Y. (2016) Service Science and the Information Professional. Chandos Publishing, Elsevier, Oxford.

[4] Shostack, G.L. (1982) How to Design a Service. European Journal of Marketing, 16, 49-63. https://doi.org/10.1108/EUM0000000004799

[5] Bitner, M.J., Ostrom, A.L. and Morgan, F.N. (2008) Service Blueprinting: A Practical Technique for Service Innovation. California Management Review, 50, 66-94. https://doi.org/10.2307/41166446

[6] Power, M. The Risk Management of Nothing. 2009. Accounting, Organizations and Society, 34, 849-855. https://doi.org/10.1016/j.aos.2009.06.001

[7] Fragnière, E. and Junod, N. (2010) The Emergent Evolution of Human Risks in Service Companies Due to "Control Industrialization": An Empirical Research. Journal of Financial Transformation, 30, 169-177.

[8] Zomerdijk, L.G. and Voss, C.A. (2010) Service Design for Experience-Centric Services. Journal of Service Research, 13, 67-82. https://doi.org/10.1177/1094670509351960

[9] Li, P.Z., Zhang, W.M. and Yu, M. (2013) Modeling of Service Delivery System for Service Enhanced Product Design: An Approach to Improve Service Performance. Journal of Applied Sciences, 13, 4644-4652. https://doi.org/10.3923/jas.2013.4644.4652

[10] Springer, A.C. and Steiguer, J.E. (2011) Social Network Analysis: A Tool to Improve Understanding of Collaborative Management Groups. Journal of Extension, 49, 1-8.

[11] Kim, H.M. (2012) Graphical Analyses of International Relations: On the Determinants of Militarized Conflicts. The Social Science Journal, 49, 42-60. https://doi.org/10.1016/j.soscij.2011.08.002

[12] Crnovrsanin, T., Muelder, C.W., Faris, R., Felmlee, D. and Ma, K.-L. (2014) Visualization Techniques for Categorical Analysis of Social Networks with Multiple Edge Sets. Social Networks, 37, 56-64. https://doi.org/10.1016/j.socnet.2013.12.002

[13] Sheng, Q.Z., Maamar, Z., Yao, L., Szabo, C. and Bourne, S. (2014) Behavior Modeling and Automated Verification of Web Services. Information Sciences, 258, 416-433. https://doi.org/10.1016/j.ins.2012.09.016

[14] Bernardoni, B.J., Deckro, R.F. and Robbins, M.J. (2013) Using Social Network Analysis to Inform Stabilization Efforts. Military Operations Research, 18, 37-60.

[15] Bélanger, J. and Edwards, P. (2013) The Nature of Front-Line Service Work: Distinctive Features and Continuity in the Employment Relationship. Work, Employment and Society, 27, 433-450. https://doi.org/10.1177/0950017013481877

[16] Ferràndiz-Vindel, I.-M. and Jiménez, B.C. (2011) The Sociogram: The Analysis of Interpersonal Relationships in Higher Education. Journal of International Education Research, 7, 9-14. https://doi.org/10.19030/jier.v7i5.6111

[17] Appleton, J.V., Terlektsi, E. and Coombes, L. (2013) The Use of Sociograms to Explore Collaboration in Child Protection Conferences. Children and Youth Services Review, 35, 2140-2146. https://doi.org/10.1016/j.childyouth.2013.09.004 
[18] De Fretes, F., Utomo, W.H. and Manongga, D. (2012) Application of Social Network Analysis for Mapping Patterns of the Learning Process in LPIA Tambun. International Journal of Computer Science, 9, 91-97.

[19] Dudenhöffer, S. and Dormann, C. (2012) Customer-Related Social Stressors and Service Providers' Affective Reactions. Journal of Organizational Behavior, 34, 520-539.

[20] Hancock, P.G. and Raeside, R. (2010) Analyzing Communication in a Complex Service Process: An Application of Social Network Analysis in the Scottish Prison Service. Journal of the Operational Research Society, 61, 265-274. https://doi.org/10.1057/jors.2008.145

[21] Koçak, G. (2014) Social Networks and Social Network Analysis. International Journal of Business and Social Science, 5, 126-135.

[22] Giri, B.E., Manongga, D. and Iriani, A. (2014) Using Social Networking Analysis (SNA) to Analyze Collaboration between Students (Case Study: Students of Open University in Kupang). International Journal of Computer Applications, 85, 39-44.

[23] Ahuja, G., Soda, G. and Zaheer, A. (2011) The Genesis and Dynamics of Organizational Networks. Organization Science, 23, 434-448.

[24] Ekmekci, O. (2013) Promoting Collaboration in Health Care Teams through Interprofessional Education: A Simulation Case Study. International Journal of Higher Education, 2, 78-83.

[25] Khalili, A. (2012) The Role of Emotional Intelligence in the Workplace: A Literature Review. International Journal of Management, 29, 355-370.

[26] Mayer, J.D. and Salovey, P. (1993) The Intelligence of Emotional Intelligence. Intelligence, 17, 433-442.

[27] Goleman, D. (2001) Emotional Intelligence. Issues in Paradigm Building, Consortium for Research on Emotional Intelligence in Organizations, 13-27.

[28] Calabrese, A. and Corbò, M. (2014) Design and Blueprinting for Total Quality Management Implementation in Service Organizations. Total Quality Management \& Business Excellence, 26, 719-732.

[29] Ganguli, S. and Kumar Roy, S. (2013) Conceptualisation of Service Quality for Hybrid Services: A Hierarchical Approach. Total Quality Management \& Business EXcellence, 24, 1202-1218. https://doi.org/10.1080/14783363.2013.814293

[30] Kleinbaum, A.M. and Stuart, T.E. (2013) Inside the Black Box of the Corporate Staff: Social Networks and the Implementation of Corporate Strategy. Strategic Management Journal, 35, 24-47.

[31] Gloor, P.A., Grippa, F., Putzke, J., Lassenius, C., Fuehres, H., Fischbach, K. and Schoder, D. (2012) Measuring Social Capital in Creative Teams through Sociometric Sensors. International Journal of Organisational Design and Engineering, 2, 380-401.

[32] Kumar, A., Heide, J.B. and Wathne, K.H. (2011) Performance Implications of Mismatched Governance Regimes across External and Internal Relationships. Journal of Marketing, 75, 1-17. https://doi.org/10.1509/jmkg.75.2.1

[33] Powell, J.L. and Owen, T. (2011) Actor Network Theory and Social Science: Possibilities and Implications. Journal of Public Administration and Governance, 1, 140-157. https://doi.org/10.5296/jpag.v1i2.947

[34] Suárez-Barraza, M.F. and Ablaned Rosas, J.H. (2014) Total Quality Management Principles: Implementation Experience from Mexican Organisations. Total Quality Management \& Business Excellence, 25, 546-560. 
https://doi.org/10.1080/14783363.2013.867606

[35] Oberle, D., Barros, A., Kylau, U. and Heinzl, S. (2013) A Unified Description Language for Human to Automated Services. Information Systems, 38, 155-181. https://doi.org/10.1016/j.is.2012.06.004

[36] Osterwalder, A. and Pigneur, Y. (2011) Business Model Generation: A Handbook for Visionaries, Game, Changers, and Challengers. New Generation. Pearson.

[37] Osterwalder, A., Pigneur, Y., Bernarda, G. and Smith, A. (2015) Value Proposition Design. Pearson.

[38] Kaplan, L.B. and Jacoby, J. (1972) The Components of Perceived Risk. In: Proceedings of the Third Annual Conference of the Association for Consumer Research, Department of Psychological Sciences, Purdue University Advertising Research Department, 382-393.

[39] Banerjee, B. (2016) Enterprise Risk Management. The Management Accountant, 51, 66-72.

[40] Beasley, M.S., Clune, R. and Hermanson, D.R. (2005) Enterprise Risk Management: An Empirical Analysis of Factors Associated with the Extent of Implementation. Journal of Accounting and Public Policy, 24, 521-531. https://doi.org/10.1016/j.jaccpubpol.2005.10.001

[41] Nocco, B.W. and Stulz, R.M. (2006) Enterprise Risk Management: Theory and Practice. Journal of Applied Corporate Finance, 18, 8-20.

https://doi.org/10.1111/j.1745-6622.2006.00106.x

[42] Gordon, L.A., Loeb, M.P. and Tseng, C.-Y. (2009) Enterprise Risk Management and Firm Performance: A Contingency Perspective. Journal of Accounting and Public Policy, 28, 301-327. https://doi.org/10.1016/j.jaccpubpol.2009.06.006

[43] Hoyt, R.E. and Liebenberg, A.P. (2011) The Value of Entreprise Risk Management. The Journal of Risk and Insurance, 78, 795-822. https://doi.org/10.1111/j.1539-6975.2011.01413.x

[44] Leung, B.P. and Silberling, J. (2006) Using Sociograms to Identify Social Status in the Classroom. California School Psychologist, 11, 57-61. https://doi.org/10.1007/BF03341115

[45] Jamali, M. and Abolhassani, H. (2006) Different Aspects of Social Network Analysis. Web Intelligence, 66-72.

[46] Padgett, J.F. and Ansell, K.C. (1993) Robust Action and the Rise of the Medici, 1400-1434. American Journal of Sociology, 98, 1259-1319. https://doi.org/10.1086/230190

[47] Hogan, B. (2007) Using Information Networks to Study Social Behavior: An Appraisal. Bulletin of the IEEE Computer Society Technical Committee on Data Engineering, 1-9.

[48] Neville, D. and Crossman, L. (2013) A Blueprint for Mapping and Modelling Ecosystem Services. Ecosystem Services, Special Issue on Mapping and Modelling Ecosystem Services, 4, 4-14.

[49] Lovelock, C., Wirtz, J., Lapert, D. and Munos, A. (2014) Service Marketing. 7th Edition, Pearson Education France. 